\title{
REVIEW
}

\section{A Systematic Meta-ethnographic Review of the Beneficial Outcomes of International Internships to Student Pharmacists}

\author{
Shaylee C. Peterson, BScPharm, ${ }^{a}$ Maria A. Paiva, PharmD, ${ }^{b}$ Kyle John Wilby, PharmD ${ }^{c}$ \\ ${ }^{\text {a }}$ University of British Columbia, Vancouver, Canada \\ ${ }^{\mathrm{b}}$ Sidra Medical and Research Center, Doha, Qatar \\ ${ }^{\mathrm{c}}$ College of Pharmacy, Qatar University, Doha, Qatar \\ Submitted August 2, 2016; accepted November 18, 2016; published September 2017.
}

Objective. To describe the benefits that pharmacy students gain by completing international internships as a part of their pharmacy education.

Methods. A systematic literature search was conducted from database inception to November 2016. Articles that reported on any measure of outcome or impact on student learning were included in the study. A meta-ethnographic approach was used to translate and synthesize findings.

Results. Analysis of the reported outcomes produced nine distinct themes: cultural awareness, collaboration, communication, clinical skills, knowledge, adaptability, compassion, confidence, and personal growth.

Conclusion. Pharmacy students experienced many benefits that align with program competencies. The most frequently described benefits were development of clinical skills and compassion.

Keywords: pharmacy, medical education, culture, international, internship

\section{INTRODUCTION}

Canadian and American accreditation standards require that experiential learning be a significant component of first degree (bachelor's or PharmD) pharmacy education. ${ }^{1,2}$ The Accreditation Council for Pharmacy Education (ACPE) in the US requires 300 hours of introductory pharmacy practice experience and 1440 hours of advanced pharmacy practice experience. ${ }^{1}$ Similarly, the Canadian Council for Accreditation Pharmacy Programs (CCAPP) requires 1600 hours of experiential education for PharmD and 640 hours for bachelor's degree students. ${ }^{2}$ These bodies also mandate students to be exposed to diverse practice settings and patient groups. ACPE states that core rotations should take place in a domestic setting so students are prepared to practice in the US, but elective rotations may be completed internationally. ${ }^{1}$

The concept of global health education is becoming increasingly common and numerous descriptions of international rotations for pharmacy students have been published. Cultural competence is also being recognized as a necessary skill for pharmacists and other health care providers. ${ }^{3}$ Cultural competency in the health care setting is an ongoing process that requires cultural awareness,

Corresponding Author: Kyle John Wilby, PO Box 2713, College of Pharmacy, Qatar University, Doha, Qatar. Tel: +974-4403-5606. Fax: +974-4403-5551. E-mail: kjw@qu. edu.qa cultural knowledge, cultural skill, cultural encounters and cultural desire. ${ }^{4}$ Furthermore, cultural encounters should not be limited to a few patients of a certain background; students should be exposed to many patients to appreciate diversity within a perceived cultural group. Both the ACPE and CCAPP, who set standards for pharmacy programs in the US and Canada, require students to be competent in a culturally diverse setting. ${ }^{1,2}$ Various educational methods to increase the cultural competence of health care providers have been described in the literature. Formats investigated include lectures, discussion groups, case scenarios, interviews, role-play, clinical experiences and cultural immersion. ${ }^{3}$ However, cultural competency is not something that can be easily learned or assessed. Immersive experiences, including educational rotations in a culturally diverse setting, appear to be an ideal method to achieve cultural competency.

A systematic review of the medical literature demonstrated that completion of international electives leads to increased diagnostic skill, confidence and cultural competence in medical students. ${ }^{5}$ Similarly, some pharmacy programs have developed international rotations for their students to address the development of cultural competency. ${ }^{6-8}$ Despite the wide uptake of these rotations with this objective, their utility in helping pharmacy students develop skills and competencies required for pharmacy practice has yet to be systematically reviewed. In 


\section{American Journal of Pharmaceutical Education 2017; 81 (7) Article 5974.}

fact, other potential benefits of international rotations to the pharmacy students who complete them, to the collaborating institutions, or to the patients treated have yet to be systematically quantified or synthesized. This review will describe the benefits that pharmacy students gain from completing international rotations (outside the country of the educational institution) as a part of their pharmacy education.

\section{METHODS}

A search of literature available until November 13, 2016, was conducted. MEDLINE, Embase, Cochrane Central Register of Controlled Trials (CENTRAL) and Google Scholar were searched for relevant trials published in English. The following search terms were combined: pharmacy, pharmacy education, clerkship, preceptorship, internship, internship, residency, education program and when required to narrow results, international, travel, abroad, and culture were included. Manual searches of key journals, including the American Journal of Pharmaceutical Education, Pharmacy Education Journal, International Journal of Health Sciences Education and Currents in Pharmacy Teaching and Learning, were completed to capture any non-indexed (ie, early online) articles published between December 2015 and November 2016. The references of relevant literature were also screened for inclusion. Any article that described an international pharmacy internship in English for pharmacy students of any level (ie, entry to practice students, residents or graduate students) was eligible for inclusion. An international internship was defined as one that took place in a different country from where the program was based. Only internships that were eligible for credit toward an accredited pharmacist training program were included. To be included in the review, articles must have described, by any method, outcomes or impact on the students who completed the internship. Abstracts were excluded.

The objective of this review is to capture all published benefits of international internships to pharmacy students; hence, the outcomes were not pre-defined. Any reported outcome of an internship that was presented as a benefit to the student who completed the internship was included. This included student development of specific competencies, awareness or skills, and any other positive development identified as personally relevant by students. Outcomes were extracted regardless of the methodology used to obtain them or the format in which they were presented.

The outcomes of international internships varied in quality and methodology. Authors report on different learning outcomes and utilize different strategies to measure them. The majority of published outcomes are reported qualitatively. Traditionally, the technique used to summarize qualitative literature is a narrative review. Although narrative reviews allow for expert insight and interpretation of the literature, the methodology fails to synthesize the body of literature being investigated. Instead, meta-ethnography has been proposed as a methodology to overcome these limitations. ${ }^{9}$

To conduct meta-ethnography, authors must transfer ideas across different studies, but retain the original meaning of the unsynthesized data. The seven steps of Noblit and Hare's meta-ethnography are getting started, deciding what is relevant to the initial interest, reading the studies, determining how the studies are related, translating the studies into one another, synthesizing the translations, and expressing the synthesis. ${ }^{9-11}$

Two investigators carefully read the studies and extracted and documented all relevant outcomes. Outcomes described by any method, including survey results, direct quotes from student reflections, or prose summarizing student reflections were extracted. Each outcome was then individually summarized using a short descriptive word or phrase. These phrases were then reviewed and similar ideas were grouped under a single theme. A table was created that identified these themes and the supporting evidence found in each of the included studies. To ensure the intended meaning was conveyed, the terminology used in the original paper was preserved. This table serves as a method of translating the findings of each of the unique studies into one another. To synthesize the translation, a figure was created to visually represent the frequency of themes reported in the studies assessed. Each outcome was weighed equally regardless of the size or quality of the study.

\section{RESULTS}

The investigators screened 508 articles. Of which 426 were left after duplicates were removed. Twentyone articles were identified for full-text review after titles and abstracts were screened. Ten articles met the criteria for inclusion. ${ }^{6-8,12-19}$ One experience was reported over a 2-part series for which we counted as one article. ${ }^{16,17}$ Reasons for exclusion of other articles are listed in Figure 1.

Of the 10 papers of international pharmacy internships identified for the review, eight took place in developing countries. ${ }^{6,7,12-18}$ Five of the internships were medical mission and were facilitated through partnerships with organizations that coordinated the missions. ${ }^{12-17}$ Time spent abroad varied from 10 days to six weeks, with several internships involving significant preparatory work prior to departure. The student activities varied between internships, but the majority involved providing 
American Journal of Pharmaceutical Education 2017; 81 (7) Article 5974.

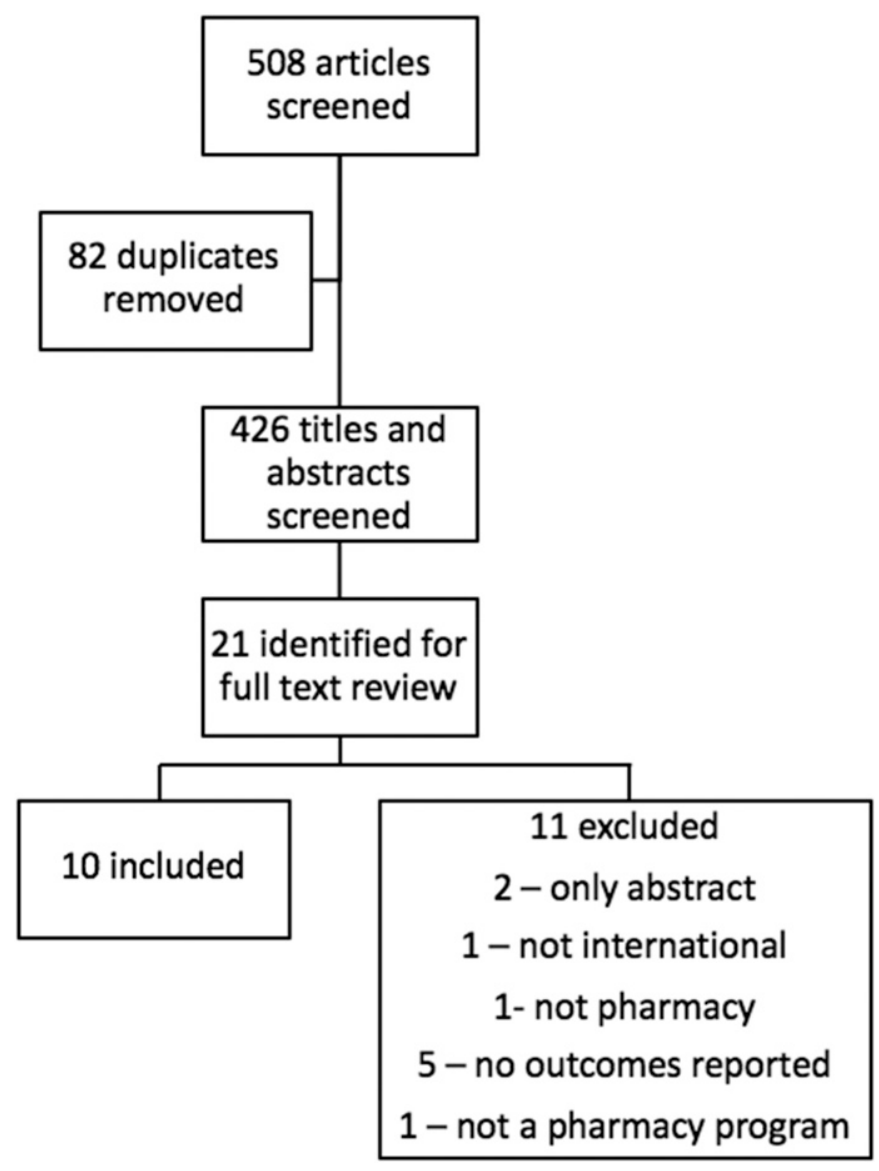

Figure 1. Flow Diagram of Search Strategy with Reasons for Exclusion of Identified Articles.

direct patient care in the form of making therapeutic recommendations, counseling and dispensing medications. The most frequent methods for reporting outcomes were descriptions or direct quotes from student reflections and follow-up surveys. One study used a validated instrument to assess cultural competency before and after the internship. ${ }^{13}$ A summarized description of the included papers can be found in Table 1 .

A review of the outcomes extracted revealed nine distinct themes: cultural awareness, collaboration, communication, clinical skills, knowledge, adaptability, compassion, confidence, and personal growth. Outcomes were categorized under one of these themes when the data suggested the students had developed in one of these domains. The most commonly reported outcomes were related to development of clinical skills and compassion (both reported in seven studies). The development of collaboration and communication skills, as well as general personal growth of the student were each identified as outcomes in six studies. Five studies reported improved cultural awareness as an outcome, and three studies reported students having improved adaptability, knowledge and confidence. References to interdisciplinary work, teamwork and knowledge of professional role or of the role of other health care providers were all considered to be a part of the "collaboration" theme. Similarly, outcomes described as compassion, altruism, desire to serve the underserved or patience were grouped under the "compassion" theme. "Adaptability" encompassed outcomes describing adaptability or flexibility of students to work in new environments, and "confidence" encompassed reports of students stepping out of their comfort zones or developing leadership attributes or confidence. "Cultural awareness" included outcomes referencing cultural competency, awareness or sensitivity. "Communication" was frequently described using the exact term in the literature, but networking and establishing new relationships were also considered communication. "Clinical skills" included the development of other skills required to practice as a pharmacist, such as literature evaluation, assessment of patients or making therapeutic recommendations. Alternatively, the theme "knowledge" included improved knowledge of disease states or medications. The final theme identified was "personal growth." This theme encompassed a broader variety of reflections that were presented as meaningful to students on an individual level. Included in this theme was spiritual growth, personal reward, influence on future career path, complementary skills that would not have been developed otherwise, improved precepting (teaching) ability and personal growth. Table 2 displays the common themes and the evidence extracted from each of the papers to support each theme.

These results were synthesized visually in Figure 2. The nine domains extracted that represent benefits to pharmacy students who partake in international internships are summarized in Figure 2 that conveys relative frequencies.

\section{DISCUSSION}

In this systematic, meta-ethnographic review we highlight the potential positive contributions of international experiences to pharmacy student education. To our knowledge, this is the first study that synthesized and described the benefits in student pharmacists specifically.

The skills and traits identified are important for pharmacists working in today's globalized world and are in line with the goals that CCAPP and ACPE set forth. Both ACPE and CCAPP require students to be able to provide care to people of different cultures, values, beliefs and customs, to be able to communicate and collaborate with other health care providers, and to develop adequate clinical knowledge and skills. ${ }^{1,2}$ Both require pharmacy practice experience be a part of all programs, and the Canadian standards outline that students should be able to practice 
American Journal of Pharmaceutical Education 2017; 81 (7) Article 5974.

Table 1. Description of Articles Used in Evaluating the Beneficial Outcomes of International Internships

\begin{tabular}{|c|c|c|c|c|c|}
\hline Reference & $\begin{array}{l}\text { Duration and } \\
\text { Location }\end{array}$ & $\begin{array}{l}\text { Setting (Hospital/ } \\
\text { Community) }\end{array}$ & Rotation Activities & $\begin{array}{l}\text { No. Students } \\
\text { Assessed }\end{array}$ & $\begin{array}{l}\text { Assessment } \\
\text { Methods }\end{array}$ \\
\hline$\overline{\text { Black }^{19}}$ & 4-6 weeks Qatar & $\begin{array}{l}\text { University pharmacy } \\
\text { faculty }\end{array}$ & $\begin{array}{l}\text { Student instruction } \\
\text { and project work }\end{array}$ & 11 & Follow-up survey \\
\hline Bress $^{8}$ & 5 weeks Australia & $\begin{array}{l}\text { Renal transplant } \\
\text { center }\end{array}$ & $\begin{array}{l}\text { Patient care, patient } \\
\text { education, colleague } \\
\text { education }\end{array}$ & 2 & Student reflection \\
\hline Brown $^{\mathrm{a}, 16,17}$ & $\begin{array}{l}\text { Brazil, Costa Rica, } \\
\text { Dominican } \\
\text { Republic, } \\
\text { Guatemala }\end{array}$ & Medical clinic & $\begin{array}{l}\text { Medication inventory } \\
\text { management, physical } \\
\text { assessment, triaging, } \\
\text { medication selection, } \\
\text { patient case presentation }\end{array}$ & 36 & $\begin{array}{l}\text { Pre- and post- } \\
\text { surveys }\end{array}$ \\
\hline Davies $^{6}$ & 27 days Botswana & $\begin{array}{l}\text { Community clinic } \\
\text { and hospital }\end{array}$ & $\begin{array}{l}\text { Observation, counseling, } \\
\text { dispensing, drug } \\
\text { preparation, vital signs, } \\
\text { vaccinations, consults }\end{array}$ & $\begin{array}{l}5 \text { pharmacy, } \\
11 \text { nursing }\end{array}$ & $\begin{array}{l}\text { Reflection paper, } \\
\text { follow-up survey }\end{array}$ \\
\hline Flores $^{\mathrm{a}, 12}$ & $\begin{array}{l}\text { 10-15 days } \\
\text { Zambia and } \\
\text { Nicaragua }\end{array}$ & Rural medical clinic & $\begin{array}{l}\text { Set up and maintain } \\
\text { functioning pharmacy } \\
\text { and provide education }\end{array}$ & 10 & $\begin{array}{l}\text { Exit interview, } \\
\text { post-trip survey }\end{array}$ \\
\hline Gourley $^{18}$ & $\begin{array}{l}30 \text { days Many } \\
\text { countries }\end{array}$ & Various & Not described & 152 & $\begin{array}{l}\text { Follow-up survey, } \\
\text { phone interview } \\
\text { (12 students) }\end{array}$ \\
\hline Pauly ${ }^{\mathrm{a}, 15}$ & $\begin{array}{l}\leq 2 \text { weeks Brazil, } \\
\text { Costa Rica, } \\
\text { Dominican } \\
\text { Republic, } \\
\text { Guatemala }\end{array}$ & Medical clinic & $\begin{array}{l}\text { Triage, diagnostics and } \\
\text { pharmacy (filling or } \\
\text { compounding } \\
\text { medications) }\end{array}$ & 5 & Follow-up survey \\
\hline Ward $^{\mathrm{a}, 14}$ & 10 days Jamaica & Urban and rural & $\begin{array}{l}\text { Triage, physical assessment, } \\
\text { interventions, dispensing, } \\
\text { education }\end{array}$ & 6 & $\begin{array}{l}\text { Reflection paper, } \\
\text { self- assessment } \\
\text { survey }\end{array}$ \\
\hline Werrenmeyer $^{\mathrm{a}, 13}$ & $\begin{array}{l}10 \text { days } \\
\text { Guatemala }\end{array}$ & $\begin{array}{l}\text { Rural ambulatory } \\
\text { clinic }\end{array}$ & $\begin{array}{l}\text { Dispensing, counseling, } \\
\text { quality improvement }\end{array}$ & 4 & $\begin{array}{l}\text { Student journals, } \\
\text { pre- and post-trip } \\
\text { IAPCC-SV survey }\end{array}$ \\
\hline Wietholter $^{7}$ & $\begin{array}{l}28 \text { days South } \\
\text { Africa }\end{array}$ & Acute care & Not described & Not stated & $\begin{array}{l}\text { Student reflection, } \\
\text { pre- and post-trip } \\
\text { survey }\end{array}$ \\
\hline
\end{tabular}

${ }^{a}$ Partnered with medical mission organization

${ }^{\mathrm{b}}$ Inventory for Assessing the Process of Cultural Competence - Student Version

with compassion and be able to adapt working in a variety of settings. The results of this review suggest that including international internships in pharmacy programs is an effective way to achieve these standards.

A systematic review of the benefits of international health electives to medical students found similar results to our review. ${ }^{5}$ Their findings included strengthening of existing and learning new diagnostic skills, improved self-confidence, increased knowledge of tropical diseases and immigrant health, cultural competency and increased desire to provide care to the underserved. Seeing similar results in medical literature increased our confidence about the validity of our results. Also identified as an outcome in the aforementioned systematic review was an increased propensity for medical students who completed international internships to choose primary care specialties, seek employment in low income clinics and pursue graduate education in public health. These outcomes have yet to be assessed in pharmacy students completing international rotations and an area for future research.

Since the outcomes extracted in this review were not pre-specified, we believe we have captured all of the published benefits of international internships to pharmacy students. Because the review was not limited to the extraction of specific outcomes, selection bias of outcomes 
American Journal of Pharmaceutical Education 2017; 81 (7) Article 5974.

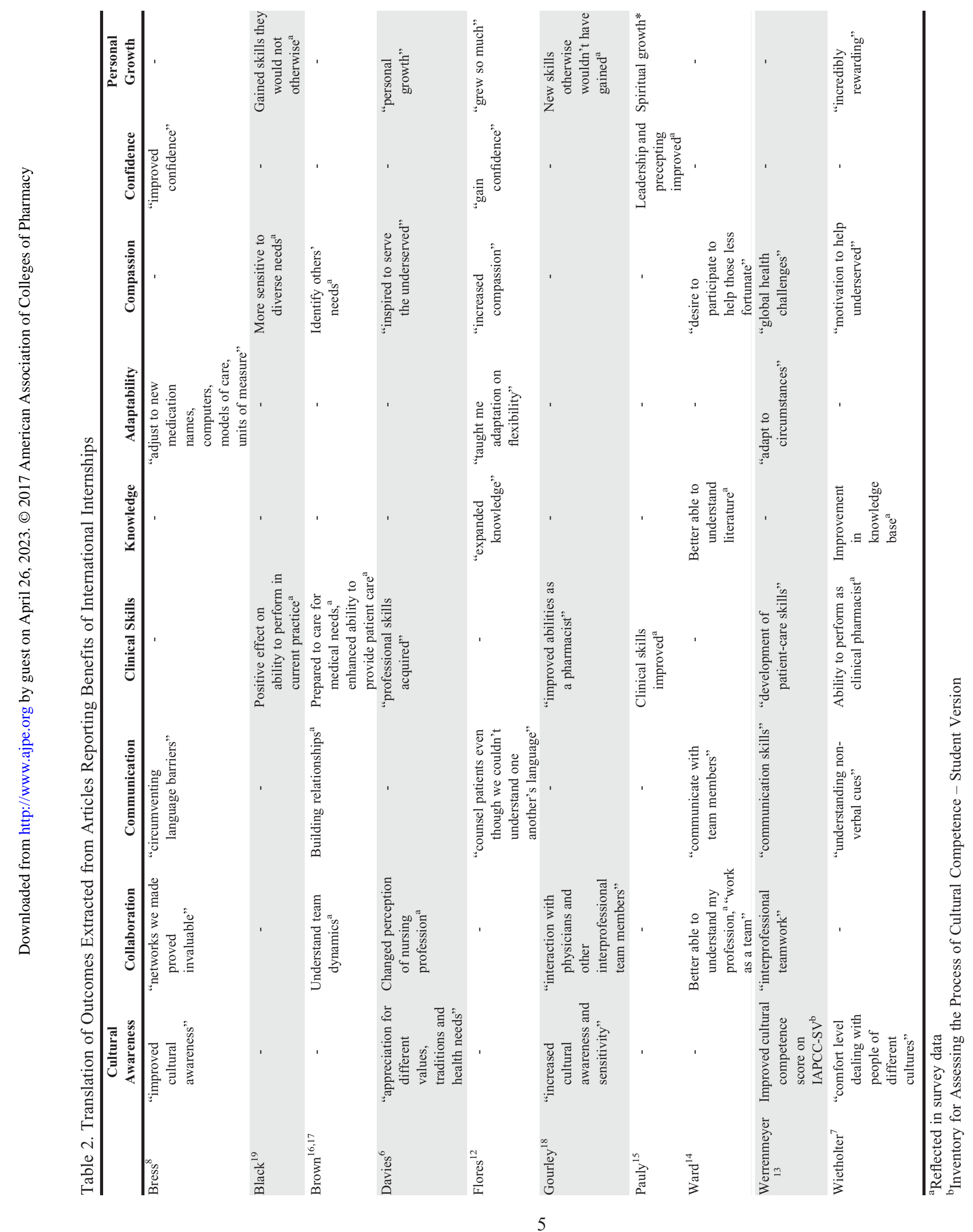




\section{American Journal of Pharmaceutical Education 2017; 81 (7) Article 5974.}

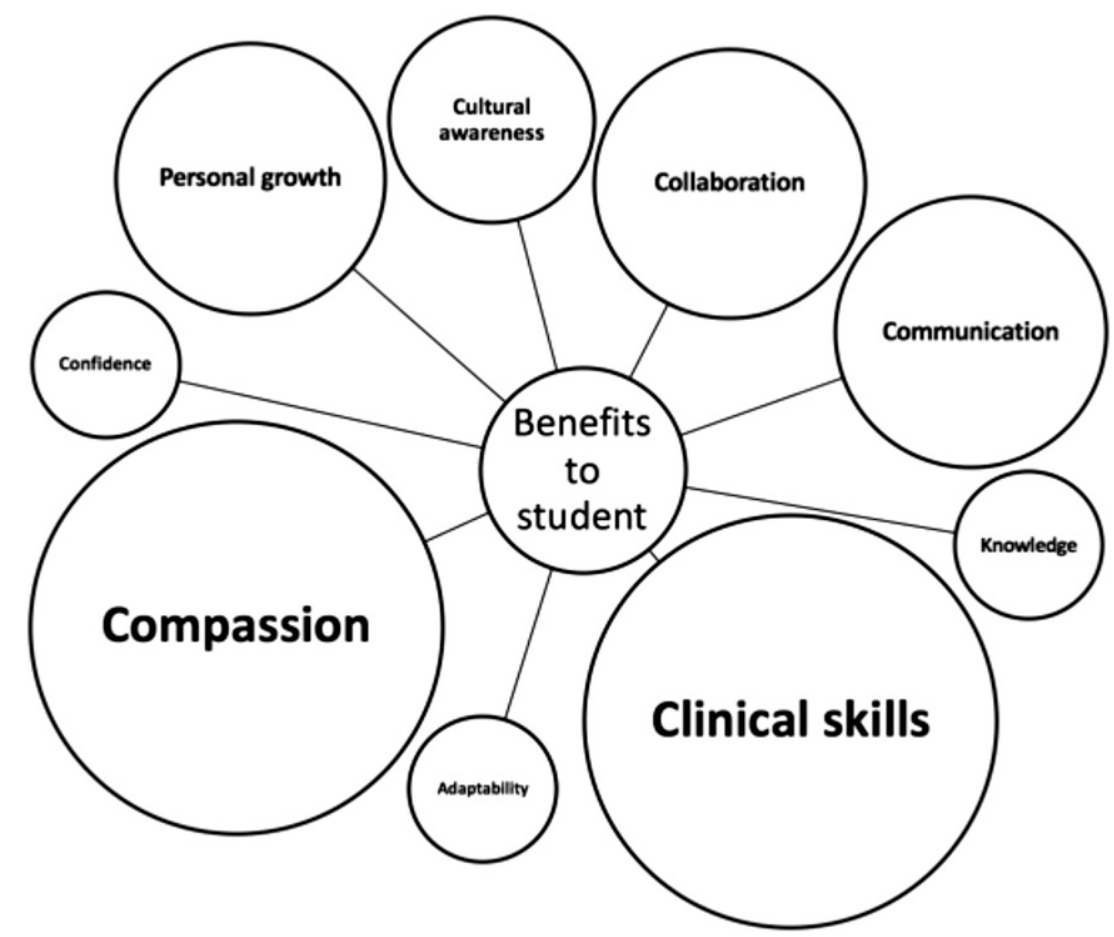

Figure 2. Graphical Representation of Translation Synthesis Results with Frequency of Identified Themes Represented by Size.

from the various articles should have been minimized. The purpose of conducting a systematic literature search prior to the meta-ethnographic review was to ensure all relevant papers were captured. Although there were challenges in conducting the literature review due to poor indexing of qualitative studies and a lack of consistency in key words used to describe studies pertaining to international pharmacy student internships, we believe most relevant papers were identified. This was achieved by a thorough examination of the references of relevant articles, manual review of key journals and an exhaustive search of the unindexed Google Scholar search engine. Interestingly, it was suggested by Noblit and Hare that meta-ethnography does not actually require all existing literature be synthesized in one review. ${ }^{9}$ It is also acceptable to limit the number of studies reviewed if it is felt that saturation of ideas or themes has been achieved. We believe our results achieved saturation, as demonstrated by the repetitive nature of themes presented in Table 2 .

Despite attempts to make this review as rigorous and scientifically valid as possible, limitations do exist. The focus of this review was to identify the benefits of international internships to pharmacy students but perhaps a review of all outcomes, including those perceived as negative would have been more useful to help pharmacy school faculty or administrators decide whether to implement an international internship. However, no negative outcomes were reported in any of the papers included in this review. This could be suggestive of a publication bias present in the literature. It would be inappropriate to assume that no students have had any negative experiences or faced any challenges while completing international pharmacy internships. It should also be noted that not all international pharmacy internships have published descriptions or assessments, so this review may not provide a completely holistic summary of all potential benefits.

The articles included in this review described student internships that varied in location, setting, duration and activities. Students will acquire different skills depending on the setting and activities of the internship they complete. As such, the intent of this review is not to suggest that all international internships will provide all nine benefits described. However, this review highlights the most common benefits that can be expected from international educational experiences. Of note, each outcome identified appeared in several papers, which suggests there is significant overlap between internships, despite their differences in their logistics and content.

There are some methodological limitations because of the nature of the papers synthesized in this review. Quality of the papers was not assessed or considered in the synthesis of outcomes. This decision was made partly because of the challenges involved in assessing 


\section{American Journal of Pharmaceutical Education 2017; 81 (7) Article 5974.}

qualitative, descriptive literature, and also to avoid limiting the review by excluding relevant experiences. The methods used to create Figure 2 may also be subject to criticism because equal weight was assigned to each outcome reported in each paper regardless of the number of students assessed. Figure 2 is not a complete representation of all of the data, which are better described in the tables, but rather a visually synthesized summary of the results incorporating frequency of reporting.

Areas for future research include capturing challenges students may face pre-, during, and post- international internships, other stakeholders' perspectives, and if the described beneficial outcomes can be achieved in local or domestic settings. Further publication of international educational experiences by stakeholders will help to strengthen the body of evidence. Development and utilization of a valid tool by researchers to assess outcomes of these rotations would also be beneficial and would allow for a more direct comparison of outcomes between varied rotations.

\section{CONCLUSION}

This review utilized the novel strategy of metaethnography to analyze and summarize the benefits of international internships to pharmacy students. Students can expect to develop a range of skills, including communication, collaboration, and clinical skills, as well as improve their knowledge, compassion, confidence, and cultural awareness. Students are also likely to experience some degree of personal growth and development by partaking in these rotations. The results of this review demonstrated tangible gains for pharmacy students that align with ACPE and CCAPP competency standards across a spectrum of international settings.

\section{REFERENCES}

1. Accreditation Council for Pharmacy Education. PharmD program accreditation. https://www.acpe-accredit.org/pharmd-programaccreditation/. Accessed September 28, 2017.

2. The Canadian Council for Accreditation of Pharmacy Programs. Accreditation standards for the first professional degree in pharmacy programs. http://ccapp-accredit.ca/wp-content/uploads/2016/01/ CCAPP_accred_standards_degree_2014.pdf. Accessed June 12, 2016. 3. Beach MC, Price EG, Gary TL, et al. Cultural competency: a systematic review of health care provider educational interventions. Med Care. 2005;43(4):356-373.
4. Campinha-Bacote J. The process of cultural competence in the delivery of health care services: a model of care. J Transcult Nurs. 2002;13(3):181-184.

5. Jeffery J, Dumont RA, Kim GY, Kuo T. Effects of international health electives on medical student learning and career choice: results of a systematic literature review. Fam Med. 2011;43(1): 21-28.

6. Davis LI, Wright DJ, Gutierrez MS, Nam JJ, Nguyen J, Waite AT. Interprofessional global service learning: a pharmacy and nursing practice experience in Botswana. Curr Pharm Teach Learn. 2015; 7(2):169-178.

7. Wietholter JP, Coetzee R, McCartney J, Gegg J, Schwinghammer TL. Development of an international advanced pharmacy practice experience (APPE) and lessons learned after implementation. Curr Pharm Teach Learn. 2014;6(2):304-312.

8. Bress AP, Filtz MR, Truong H-A, Nalder M, Vienet M, Boyle CJ. An advanced pharmacy practice experience in Melbourne, Australia: practical guidance for global experiences. Curr Pharm Teach Learn. 2011;3(1):53-62.

9. Noblit GW, Hare RD. Meta-ethnography: Synthesizing Qualitative Studies. Newbury Park, CA: SAGE Publications; 1988. 10. Britten N, Campbell R, Pope C, Donovan J, Morgan M, Pill R. Using meta-ethnography to synthesise qualitative research: a worked example. J Health Serv Res Policy. 2002;7(4):209-215.

11. Atkins S, Lewin S, Smith H, Engel M, Fretheim A, Volmink J. Conducting a meta-enthography of qualitative literature: lessons learnt. BMC Med Res Method. 2008;8:21.

12. Flores KE, Courtney LA. Development of a partnership for international rural advanced pharmacy practice experiences. Int $J$ Health Sci. 2014;2(1):Article 5.

13. Werremeyer AB, Skoy ET. A medical mission to Guatemala as an advanced pharmacy practice experience. Am J Pharm Educ. 2012;76(8): Article 156.

14. Ward CT, Nemire RE, Daniel KP. The development and assessment of a medical mission elective course. Am J Pharm Educ. 2005;69(3):Article 50.

15. Pauly JB, Poulakos MN, Fairclough JL, Chahine EB. Implementing and assessing an elective learning experience in medical missions for PGY-1 pharmacy residents. Curr Pharm Teach Learn. 2016;8(4):559-564.

16. Brown DA, Fairclough JL, Ferril MJ. Planning a pharmacy-led medical mission trip, part 4: an exploratory study of student experiences. Ann Pharmacother. 2012;46(9):1250-1255.

17. Brown DA, Ferril MJ. Planning a pharmacy-led medical mission trip, part 3: development and implementation of an elective medical mission advanced pharmacy practice experience (APPE) rotation. Ann Pharmacother. 2012;46(7-8):1111-1114.

18. Gourley DR, Vaidya VA, Hufstader MA, Ray MD, ChisholmBurns MA. An international capstone experience for pharmacy students. Am J Pharm Educ. 2013;77(3):Article 50.

19. Black EK, Wilby KJ, Jewesson PJ. International exposure to pharmacy leadership, education and practice: the early Qatar experience. Pharm Educ. 2014;14(1):70-75. 